\title{
Acute Exercise-Associated Skin Surface Temperature Changes after Resistance Training with Different Exercise Intensities
}

\author{
Martin Weigert*, Nico Nitzsche, Felix Kunert, Christiane Lösch, Lutz Baumgärtel, Henry Schulz \\ Institute of Human Movement Science and Health, Chemnitz University of Technology, Thüringer Weg 11, 09126 Chemnitz, Germany
}

Corresponding Author: Martin Weigert, E-mail: martin.weigert@hsw.tu-chemnitz.de

\section{ARTICLE INFO}

Article history

Received: October 04, 2017

Accepted: December 16, 2017

Published: January 31, 2018

Volume: 6 Issue: 1

Conflicts of interest: None

Funding: European Social Fund

\begin{abstract}
Background: Studies showed, that changes in muscular metabolic-associated heat production and blood circulation during and after muscular work affect skin temperature (T) but the results are inconsistent and the effect of exercise intensity is unclear. Objective: This study investigated the intensity-dependent reaction of $\mathrm{T}$ on resistance training. Methods: Ten male students participated. After acclimatization $(15 \mathrm{~min})$, the participants completed $3 \times 10$ repetitions of unilateral biceps curl with 30,50 or $70 \%$ of their one-repetition-maximum (1RM) in a randomized order. Skin temperature of the loaded and unloaded biceps was measured at rest $\left(\mathrm{T}_{\text {rest }}\right)$, immediately following set 1,2 and $3\left(\mathrm{~T}_{\mathrm{S} 1}, \mathrm{~T}_{\mathrm{S} 2}, \mathrm{~T}_{\mathrm{S} 3}\right)$ and 30 minutes post exercise $\left(\mathrm{T}_{1}-\mathrm{T}_{30}\right)$ with an infrared camera. Results: Two-way ANOVA detected a significant effect of the measuring time point on $\mathrm{T}\left(\mathrm{T}_{\text {rest }}\right.$ to $\left.\mathrm{T}_{30}\right)$ of the loaded arm for $30 \%\left(\mathrm{Eta}^{2}=0.85\right), 50 \%\left(\mathrm{Eta}^{2}=0.88\right)$ and $70 \% 1 \mathrm{RM}$ $\left(\mathrm{Eta}^{2}=0.85\right)$ and of the unloaded arm only for $30 \% 1 \mathrm{RM}\left(\mathrm{Eta}^{2}=0.41\right)(\mathrm{p}<0.05)$ but time effects were independent of the exercise intensity $(p>0.05)$. The $T$ values at the different measuring time points $\left(\mathrm{T}_{\text {rest }}-\mathrm{T}_{30}\right)$ did not differ between the intensities at any time point. The loaded arm showed a mean maximum $\mathrm{T}$ rise to $\mathrm{T}_{\text {rest }}$ of $1.8^{\circ} \mathrm{C}$ and on average, maximum $\mathrm{T}$ was reached approximately 5 minutes after the third set. Conclusion: This study indicate a rise of $\mathrm{T}$, which could be independent of the exercise intensity. Infrared thermography seems to be applicable to identify the primary used functional muscles in resistance training but this method seems not suitable to differentiate between exercise intensity from 30 to $70 \% 1 \mathrm{RM}$.
\end{abstract}

Key words: Thermography, Skin Temperature, Thermoregulation, Resistance Training, Muscle, Skeletal

\section{INTRODUCTION}

Infrared thermography (IRT) is a safe, quick and effective non-contact method to examine the distribution of temperature at the skin surface (T) by measuring the infrared radiation of a person (Costello et al., 2013). Hyperthermic areas may be caused by increased blood flow, inflammation, growing tumor or other tissue lesions.

In medicine, IRT is used as a breast cancer screening method and for the diagnosis of inflammations (e.g. arthritis), vascular diseases (e.g. Raynaud's phenomenon, diabetes, deep vein thrombosis) and dermatological disorders, (Jiang et al., 2005; Lahiri et al., 2012; Ring \& Ammer, 2012; Wang et al., 2004). Compared to the aforementioned applications, IRT has been rarely used in sports medicine, but it can be important for an early identification and localization of inflammations, traumatic injuries and overuse injuries (Das, Vardasca, \& Mendes, 2017; Hildebrandt, Raschner, \& Ammer, 2010; Sillero-Quintana, Gomez-Carmona, \& Fernández-Cuevas, 2017).

Apart from the applications in medicine, IRT may play an important role as a noninvasive diagnosis method in sports science. With IRT, it is possible to determine changes in T as a result of heat generation, induced by muscle contraction during physical activity due to temperature changes of body surfaces, concerning to active muscles (Chudecka, 2013). Within this context, IRT can be used to evaluate the symmetry of muscle activity in various types of exercises (Chudecka et al., 2015). For instance, it is important, that the muscles of scullers are equally involved in the performed movement to reach maximum velocity (Chudecka et al., 2015). Furthermore, studies tried to evaluate IRT as a tool for monitoring thermoregulation during and after endurance exercises (Balci, Basaran, \& Colakoglu, 2016; Fröhlich et al., 2015; Merla et al., 2010; Priego Quesada et al., 2015; Priego Quesada et al., 2016).

Another possible application area is the use of IRT for analyzing changes in T during and after resistance exercise. Here, IRT could offer indirect hemodynamic recruitment information of muscle masses during exercise-related thermal adjustment. Temperature changes that occurred in working muscle areas are transferred to superficial tissue and can be measured as skin surface temperatures via IRT. Several stud- 
ies have already dealt with changes in $\mathrm{T}$ after resistance exercise but the results have been inconsistent. Fröhlich et al. (2014) studied the T changes of different muscle groups after different resistance exercises. They found a decrease in $\mathrm{T}$ after sit ups, back extensions and lat pulls in the corresponding skin areas and almost unchanged $\mathrm{T}$ following bench press and squats. Neves et al., (2016) showed a strong acute and 15 minutes lasting decrease of $\mathrm{T}$ after biceps curls and half squat exercises whereas Formenti et al. (2016) and Neves et al. (2014) showed an acute $\mathrm{T}$ drop after resistance exercise followed by a rise of $\mathrm{T}$ over basal values. Further studies showed increased T values after biceps curl (Bartuzi, Roman-Liu, \& Wisniewski, 2012; Neves et al., 2015; Neves et al., 2016) and standing calf raise (Formenti et al., 2013).

Most of the studies to date investigating thermographic images during and after resistance training observed, that it is possible to identify the primary used muscles via IRT (Formenti et al., 2013; Formenti et al., 2016; Fröhlich et al., 2014; Neves et al., 2014; Neves et al., 2015; Neves et al., 2016). So far it is not clear how intense a load must be to cause changes in $\mathrm{T}$ and if different intensities lead to different $\mathrm{T}$ patterns during and after resistance exercise. For instance in reaction to very intense resistance training, a particularly increase or an acute drop in T occurs due to a vasoconstriction of the cutaneous blood vessels (Formenti et al., 2016; Fröhlich et al., 2014; Neves et al., 2014) is possible.

For this reason, the present study investigated the intensity-dependent reaction of $\mathrm{T}$ on the resistance exercise unilateral biceps curl in a strongly standardized protocol. We hypothesize a $\mathrm{T}$ rise of the loaded arm during and following the resistance exercise, which is augmented with increasing intensity. Furthermore, we expect no changes of T of the unloaded arm.

\section{MATERIALS AND METHODS}

\section{Participants}

10 healthy male students (age $24.5 \pm 2.0$ years; height $1.84 \pm 0.07 \mathrm{~m}$; body weight $82.8 \pm 7.1 \mathrm{~kg}$; BMI $24.3 \pm 1.6 \mathrm{~kg} / \mathrm{m}^{2}$ ) participated in the study (Table 1). Participation was voluntary and did not involve any financial compensation. Informed consent was obtained from all students involved in the study. As exclusion criteria, the following aspects were considered for every test day: infections, consumption of alcohol, caffeine or nicotine, exercise, body lotion, therapeutic treatment or massage of the upper limb region, and a meal eaten within the last two hours before the test. The study was approved by the Ethics Committee of the Chemnitz University of Technology.

\section{Study Procedure}

During the first visit, participants were informed about the procedure and the potential risks of the study and provided their written consent. Anthropometric data was collected, body weight, body mass index (BMI), and proportion of body fat calculated with the body composition analyzer InBody 720 (InBody Co., Ltd., Seoul, South Korea). Biceps skinfold thickness (BST) was measured in the middle of the muscle belly of the biceps brachii (area of the largest arm circumference) with a skinfold caliper.

Before the 1RM test, based on the procedure by (Baechle \& Earle, 2008), the participants performed a short individual warm up for the upper limbs and were familiarised with the $1 \mathrm{RM}$ exercise biceps curl by performing a warm-up set of 10 repetitions at approximately 50\% $1 \mathrm{RM}$ and 5 repetitions at approximately $75 \%$ 1RM. After the warm up, the participants performed a series of single repetitions to determine the dynamic concentric $1 \mathrm{RM}$ of the dominant right arm for the resistance exercise biceps curl with the cable pulley with two movable pulleys on a scott bench (1RM defined as the maximum amount of weight lifted with proper form through a $90^{\circ}$ range of motion for a single repetition).

During the second, third and fourth visits, the participants came to laboratory and sat for 15 minutes with naked upper body in a relaxed position for acclimatization. The room temperature during testing was $22.1 \pm 0.5^{\circ} \mathrm{C}$ and humidity $35-40 \%$. During acclimatization, the muscle belly of the right and left biceps brachii was marked with cork discs (Figure 1a), which possesses a low thermal conductivity $\left(\lambda=0.036 \mathrm{~W} \cdot \mathrm{m}^{-1} \cdot \mathrm{K}^{-1}\right)$ and is visible in thermal imaging.

The training protocol consisted of three sets with 10 repetitions biceps curl to a flexion angle of $90^{\circ}$ with the right arm (Figure 1b). Rest between the sets was two minutes. After acclimatization, the participants completed one protocol per visit on nonconsecutive days with 30,50 or $70 \%$ of the $1 \mathrm{RM}$ in randomized order. For randomization, the participants drew a number to determine the exercise intensity on each measurement day. The frequency of movement was controlled by a metronome and standardized as 1.5 s for concentric and $1.5 \mathrm{~s}$ for eccentric movement phase. If the participants could not finish a set, they got minimum support by the supervisor, so that all 10 repetitions were performed in the prescribed velocity.

Table 1. Participant characteristics $(\mathrm{N}=10)$, data presented as mean, standard deviation, minimum, maximum (BMI=body mass index, $\mathrm{BST}=$ biceps skinfold thickness, $1 \mathrm{RM}=$ one-repetition-maximum of biceps curl).

\begin{tabular}{|c|c|c|c|c|c|c|c|}
\hline & Age & Height & Weight & BMI & Body fat & BST & 1RM \\
\hline & [y & & [kg] & & & & \\
\hline Mean & 24.5 & 1.84 & 82.8 & 24.3 & 14.9 & 4.9 & 62.5 \\
\hline SD & 2.0 & 0.07 & 7.1 & 1.6 & 5.3 & 1.4 & 10.1 \\
\hline Min & 23.0 & 1.74 & 70.6 & 21.7 & 6.2 & 3.0 & 50.0 \\
\hline Max & 30.0 & 1.95 & 91.3 & 26.9 & 22.2 & 7.0 & 80.0 \\
\hline
\end{tabular}




\section{Measurement}

Thermographic images were taken with the infrared camera FLIR A35 (FLIR Systems, Inc., USA) during the following time points: at rest after 15 minutes of acclimatization $\left(\mathrm{T}_{\text {rest }}\right)$, immediately after the first, second and third set $\left(\mathrm{T}_{\mathrm{S} 1}, \mathrm{~T}_{\mathrm{S} 2}, \mathrm{~T}_{\mathrm{S} 3}\right)$, and at $1,2,3,4,5,6,7,8,9,10,15,20,25,30$ minutes post the third set $\left(\mathrm{T}_{1}\right.$ $\mathrm{T}_{30}$ ). Participants stood at a distance of $1.50 \mathrm{~m}$ from the camera in front of a white uniform background, in order to ensure that the markers of the upper body and arms were visible (Figure 1a). There was constant intensity of light and no direct ventilation in the test room during the measurement procedure because this can influence the skin temperature measurements. In addition, the methodological aspects of infrared thermography in human assessment were considered (Priego Quesada, 2017).

All thermographic images were analyzed by the same examiner with FLIR ResearchIR 4 Software (FLIR Systems, Inc., USA). This software is a tool to calculate mean skin surface temperature in a defined area by averaging the detected temperature values. To determine the mean temperature of the biceps surface at every measuring time point, a line was fitted between the two cork markers at the right arm and at the left arm in the muscle belly region of the biceps brachii. Each of this lines consisted of approximately 50 pixels with 50 temperature values between the markers and the software calculated the mean temperature of this 50 values (Figure 2). When the fitted line ran along the Vena cephalica, the line was positioned medial of the vein, because temperatures at the skin surface of blood vessels are much higher than in other skin areas. Hence a line along a vein does not represent the mean surface temperature.

For an accurate measurement of $\mathrm{T}$ of a particular region, a minimum of 25 pixels is recommended (ISO 2009). Therefore, in this study the number of pixels of the region of interest was between 40 and 60 .

Table 2 shows the parameters that were calculated for the loaded and unloaded arm.

\section{Statistical Analysis}

Data are presented as means \pm SD. Normal distribution was checked by Shapiro-Wilk test and homogeneity of variances by Levene test. Two-way ANOVA was used to test the effect of measuring time point and intensity on the surface temperature. One-way ANOVA with repeated measurements tested the time points with a significant temperature difference compared to $\mathrm{T}_{\text {rest }}$ and the influence of the intensity on
$\mathrm{T}_{\text {rest }}, \mathrm{T}_{\mathrm{S} 3}, \mathrm{~T}_{\text {max }}$, time to $\mathrm{T}_{\max }, \mathrm{T}_{30}$, and $\mathrm{T}_{\text {max }}-\mathrm{T}_{30} . \mathrm{P}$-values were Bonferroni corrected. To determine the relationship of biceps skinfold thickness (BST) and $1 \mathrm{RM}$ to $\mathrm{T}_{\mathrm{S} 3}$ and $\mathrm{T}_{\max }$ the correlation coefficient Spearmans Rho was calculated. The level of significance was 0.05 . Statistical analysis was performed using SPSS (Version 23.0 IBM, New York, USA). For graphical representation, Grapher 4.0 (Golden Software Inc., Golden, USA) was used.

\section{RESULTS}

The measuring time point had a significant effect on $\Delta \mathrm{T}$ of the loaded arm for all intensities together and for 30, 50 and

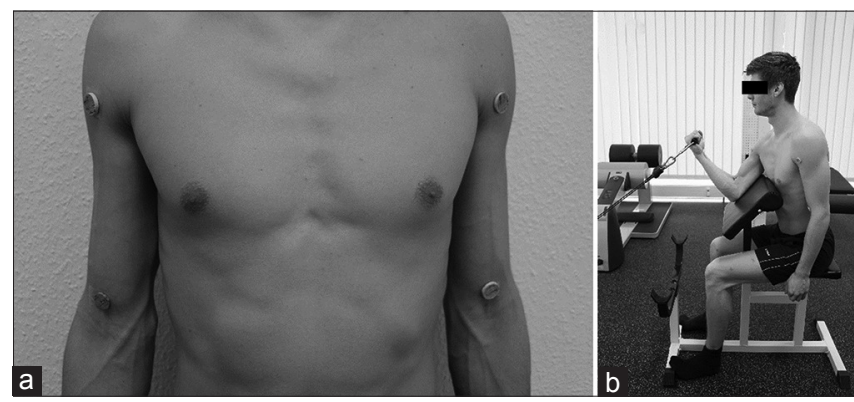

Figure 1. a) Standing position for thermographic images with fixed cork markers at the muscle belly of the right and left biceps brachii, b) Endposition of the resistance exercise biceps curl on a scott bench on the cable pulley

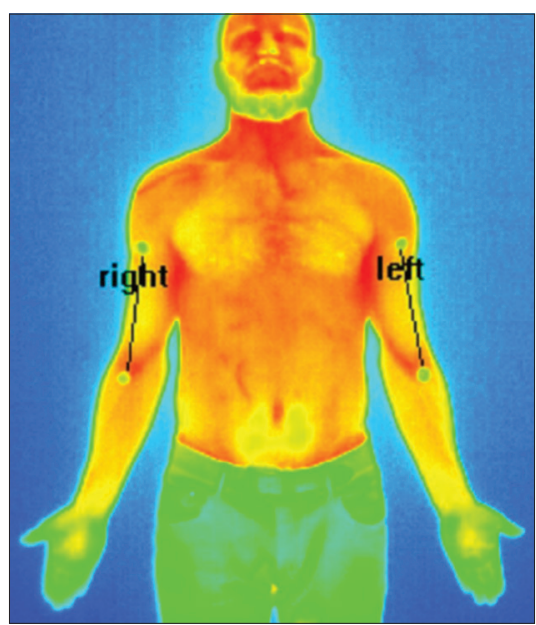

Figure 2. Thermographic image with a fitted line between the cork markers

Table 2. Parameters used to characterize the time profile of biceps surface temperature $(\mathrm{T})$.

\begin{tabular}{lll}
\hline Index abbreviation & Definition & Units \\
\hline Basal temperature $\left(\mathrm{T}_{\text {rest }}\right)$ & temperature value prior to the training & ${ }^{\circ} \mathrm{C}$ \\
$\Delta$ temperature to $\mathrm{T}_{\text {rest }}(\Delta \mathrm{T})$ & difference of measured temperature and $\mathrm{T}_{\text {rest }}$ & ${ }^{\circ} \mathrm{C}$ \\
$\mathrm{T}_{\mathrm{S} 1}, \mathrm{~T}_{\mathrm{S} 2}, \mathrm{~T}_{\mathrm{S} 3}$ & $\Delta$ temperature to $\mathrm{T}_{\text {rest }}$ following set 1,2 and 3 & ${ }^{\circ} \mathrm{C}$ \\
$\mathrm{T}_{1}, \mathrm{~T}_{2}, \mathrm{~T}_{3}, \mathrm{~T}_{4}, \mathrm{~T}_{5}, \mathrm{~T}_{6}, \mathrm{~T}_{7}, \mathrm{~T}_{8}, \mathrm{~T}_{9}, \mathrm{~T}_{10}, \mathrm{~T}_{15}, \mathrm{~T}_{20}, \mathrm{~T}_{25}, \mathrm{~T}_{30}$ & $\Delta$ temperature to $\mathrm{T}_{\text {rest }} 1-30$ min after set 3 & ${ }^{\circ} \mathrm{C}$ \\
$\mathrm{T}_{\max }$ & maximum $\Delta$ temperature & ${ }^{\circ} \mathrm{C}$ \\
$T_{\text {Time to }} \mathrm{T}_{\max }$ & time after $\mathrm{T}_{\mathrm{S} 3}$, when $\mathrm{T}_{\max }$ was recorded & min \\
$\mathrm{T}_{\max }-\mathrm{T}_{30}$ & difference of $\mathrm{T}_{\max }$ and $\mathrm{T} 30$ & ${ }^{\circ} \mathrm{C}$ \\
\hline
\end{tabular}


$70 \%$ of the 1RM. For the unloaded arm, the measuring time point had a significant effect for all intensities together and for $30 \% 1 \mathrm{RM}$. The time effects were independent of the intensity (Table 3 ).

For the loaded arm, the ANOVA of the factor intensity showed no effect for any of the measuring time points or for $\mathrm{T}_{\max }$, time to $\mathrm{T}_{\max }$ and $\mathrm{T}_{\max }-\mathrm{T}_{30}$ (Table 4 ). Lower intensities showed an earlier significant increase of the biceps surface $T$ of the loaded arm compared to $\mathrm{T}_{\text {rest }}$ : ANOVA showed a significant higher $\mathrm{T}$ of the biceps surface at $\mathrm{T}_{\mathrm{S} 2}$ to $\mathrm{T}_{15}(30 \% 1 \mathrm{RM})$, $\mathrm{T}_{\mathrm{S} 3}$ to $\mathrm{T}_{20}(50 \% 1 \mathrm{RM})$ and $\mathrm{T}_{1}$ to $\mathrm{T}_{15}(70 \% 1 \mathrm{RM})(\mathrm{p}<0.05)$. On average, $\mathrm{T}_{\max }$ was reached approximately 5 minutes after the third set $\left(T_{5}\right)$ and the time to $T_{\text {max }}$ tended $(p>0.05)$ to increase with a higher intensity (Table 4 ). After reaching $\mathrm{T}_{\text {max }}$, a slow temperature decrease on the loaded arm was observed up to the $30^{\text {th }}$ minute $\left(\mathrm{T}_{30}\right)$, but rest values were not reached again after 30 minutes and $\mathrm{T}$ was still increased by $0.4^{\circ} \mathrm{C}(\mathrm{p}<0.05)$.

The unloaded arm showed no significant difference of $\mathrm{T}$ to $\mathrm{T}_{\text {rest }}$ at any time point ( $\mathrm{p}>0.05$ ).

At $30 \% 1 \mathrm{RM}$ positive correlations of the $1 \mathrm{RM}$ with $\mathrm{T}_{\mathrm{S} 3}$, $(\mathrm{r}=0.842 ; \mathrm{p}=0.002)$ and $\mathrm{T}_{\max }(\mathrm{r}=0.661 ; \mathrm{p}=0.038)$ were found. BST showed a negative correlation with $\mathrm{T}_{\mathrm{S} 3}$ at $50 \% 1 \mathrm{RM}$ $(\mathrm{r}=-0.737 ; \mathrm{p}=0.015)$.

\section{DISCUSSION}

The present study investigated the influence of a unilateral biceps curl with different exercise intensities on the re- action of $\mathrm{T}$ in the biceps brachii muscle region. In the loaded arm, $\mathrm{T}$ increased significantly independent of the exercise intensity. The curves of the different intensities showed qualitatively similar patterns (Figure 3b). Looking at the individual profiles of the surface temperature on the loaded arm, a homogeneous pattern is shown (Figure 3c). All participants showed a rise of $\mathrm{T}$ after 30,50 and $70 \% 1 \mathrm{RM}$. Therefore, previous studies that observed, that it is possible to identify the primary used muscles via IRT during and after resistance training (Formenti et al., 2013; Formenti et al., 2016; Fröhlich et al., 2014; Neves et al., 2014; Neves et al., 2015; Neves et al., 2016) can be confirmed. Figure 4 shows an example for the visualization of the heated biceps brachii after three sets of biceps curl with the right arm.

Since blood flow was not measured in this study, we assume that the $\mathrm{T}$ changes are the result of a higher skin perfusion (Schlager et al., 2010) and/or of muscle contractions due to a change in the muscular blood circulation and muscle heat production during and after exercise (Kenny et al., 2003; Kenny et al., 2008; Krustrup et al., 2003). The resulting muscle heat is transferred to the surrounding tissue and can be measured at the surface.

Interestingly, a slight and non-significant drop in temperature was observed at 70\% 1RM after the first set. This has already been described by Formenti et al. (2016) and Neves et al. (2014) and could result from a reactive vasoconstriction of the skin vessels and may indicate a redistribution of the blood immediately after intense exercise into

Table 3. $\operatorname{Eta}^{2}$ (p-value) by ANOVA of the factors time (measurement time point) and time $\mathrm{x}$ intensity for $\Delta$ temperatures of the loaded and unloaded arm $(* \mathrm{p}<0.05)$

\begin{tabular}{llcccc}
\hline & Arm & All intensities & $\mathbf{3 0 \%}$ 1RM & $\mathbf{5 0 \%} \mathbf{1 R M}$ & $\mathbf{7 0 \%} \mathbf{1 R M}$ \\
\hline Factor time & loaded & $0.863^{*}(\mathrm{p}<0.001)$ & $0.853^{*}(\mathrm{p}<0.001)$ & $0.879 *(\mathrm{p}<0.001)$ & $0.863 *(\mathrm{p}<0.001)$ \\
& unloaded & $0.273^{*}(\mathrm{p}<0.001)$ & $0.411 *(\mathrm{p}=0.002)$ & $0.254(\mathrm{p}=0.075)$ & $0.239(\mathrm{p}=0.057)$ \\
Factor time $x$ intensity & loaded & $0.132(\mathrm{p}=0.067)$ & & & \\
& unloaded & $0.046(\mathrm{p}=0.686)$ & & & \\
\hline
\end{tabular}

Table 4. Means \pm SD of selected parameters of the loaded and unloaded arm and differences between loaded and unloaded arm (*significant difference of the loaded arm to the unloaded arm, ${ }^{*}$ significant difference to $\mathrm{T}_{\text {rest }}$ )

\begin{tabular}{llccccc}
\hline & Arm & All intensities & $\mathbf{3 0 \%}$ 1RM & $\mathbf{5 0 \%}$ 1RM & $\mathbf{7 0 \%}$ 1RM & P-value of intensity \\
\hline $\mathrm{T}_{\text {rest }}\left[{ }^{\circ} \mathrm{C}\right]$ & Loaded & $32.6 \pm 0.8$ & $32.3 \pm 0.7$ & $32.7 \pm 0.9$ & $32.9 \pm 0.9$ & 0.266 \\
& Unloaded & $32.7 \pm 0.8$ & $32.3 \pm 0.7$ & $32.7 \pm 0.9$ & $33.1 \pm 0.9$ & 0.137 \\
$\mathrm{~T}_{\mathrm{S} 3}\left[{ }^{\circ} \mathrm{C}\right]$ & Loaded & $0.8 \pm 0.5^{* \#}$ & $0.9 \pm 0.4^{* \#}$ & $0.9 \pm 0.5^{* \#}$ & $0.8 \pm 0.6^{*}$ & 0.801 \\
& Unloaded & $-0.1 \pm 0.4$ & $0.1 \pm 0.3$ & $-0.2 \pm 0.3$ & $-0.3 \pm 0.4$ & 0.064 \\
$\mathrm{~T}_{\max }\left[{ }^{\circ} \mathrm{C}\right]$ & Loaded & $1.8 \pm 0.4^{*}$ & $1.7 \pm 0.3^{* \#}$ & $1.9 \pm 0.5^{* \#}$ & $1.8 \pm 0.5^{* \#}$ & 0.570 \\
& Unloaded & $0.4 \pm 0.4^{\#}$ & $0.5 \pm 0.3^{\#}$ & $0.3 \pm 0.3^{\#}$ & $0.2 \pm 0.4$ & 0.076 \\
time to $\mathrm{T}_{\max }[\mathrm{min}]$ & Loaded & $5.4 \pm 2.1^{*}$ & $4.6 \pm 1.8^{*}$ & $5.2 \pm 2.5$ & $6.4 \pm 1.6$ & 0.143 \\
& Unloaded & $8.6 \pm 6.7$ & $9.7 \pm 7.3$ & $8.6 \pm 6.9$ & $7.4 \pm 6.4$ & 0.785 \\
$\mathrm{~T}_{\max }-\mathrm{T}_{30}\left[{ }^{\circ} \mathrm{C}\right]$ & Loaded & $1.3 \pm 0.5^{*}$ & $1.3 \pm 0.6^{*}$ & $1.5 \pm 0.5^{*}$ & $1.3 \pm 0.4^{*}$ & 0.601 \\
$\mathrm{~T}_{30}\left[{ }^{\circ} \mathrm{C}\right]$ & Unloaded & $0.5 \pm 0.4$ & $0.5 \pm 0.3$ & $0.6 \pm 0.5$ & $0.5 \pm 0.4$ & 0.879 \\
& Loaded & $0.4 \pm 0.6^{* \#}$ & $0.4 \pm 0.6$ & $0.4 \pm 0.5^{*}$ & $0.6 \pm 0.6^{*}$ & 0.650 \\
\hline
\end{tabular}




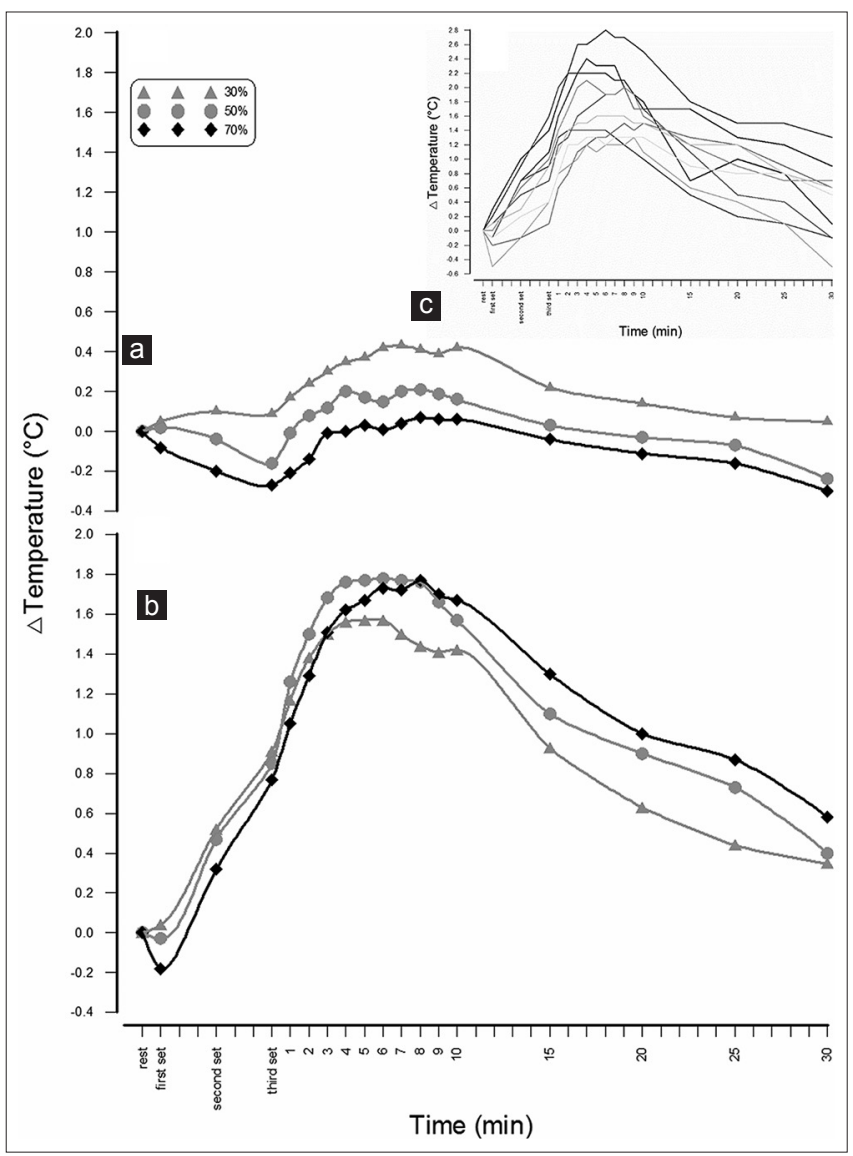

Figure 3. Average biceps surface $\Delta \mathrm{T}$ at 30,50 and $70 \%$ of $1 \mathrm{RM}$ of a) unloaded arm, b) loaded arm. c) Individual biceps surface $\Delta \mathrm{T}$ at $50 \% 1 \mathrm{RM}$ of the loaded arm for all participants.

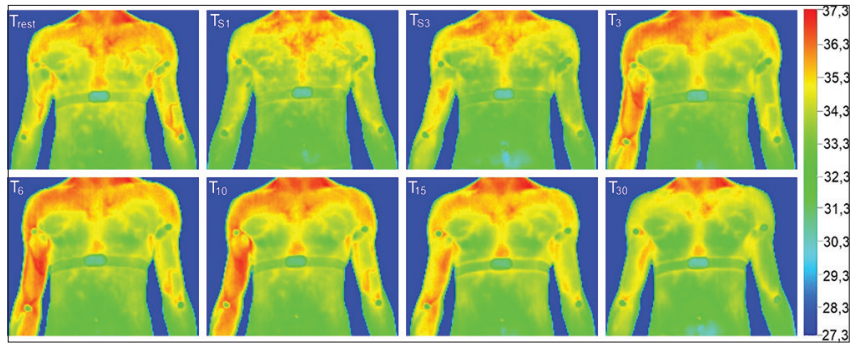

Figure 4. Thermographic images of a representative participant at the time points $\mathrm{T}_{\text {rest }}, \mathrm{T}_{\mathrm{S} 1}, \mathrm{~T}_{\mathrm{S} 3}, \mathrm{~T}_{3}, \mathrm{~T}_{6}, \mathrm{~T}_{10}, \mathrm{~T}_{15}, \mathrm{~T}_{30}(70 \% 1 \mathrm{RM}$ training protocol, right arm $=$ loaded arm)

the stressed muscle. This might be necessary to ensure the energetic and enzymatic processes for muscle contraction because a higher temperature in the muscle results in a higher enzyme activity of the ATPase and creatine kinase in the muscle fiber (Gray et al., 2011; Stienen et al., 1996).

We hypothesized, that the $\mathrm{T}$ rise of the loaded arm during and following the resistance exercise is augmented with increasing intensity but temperature changes of the skin surface in the present study were independent of the exercise intensity. In contrast, Bartuzi et al. (2012) found a significant influence of the intensity on $\mathrm{T}$ during a biceps exercise. However, it is hard to compare this study with the present one, because the exercise was static and very low intensities were chosen $(5,15,30 \%$ of maximum voluntary contraction), which had to be held for up to 5 minutes. The temperature differences to $T_{\text {rest }}$ was significant higher after the $30 \%$ load compared to the $5 \%$ load $\left(0.8^{\circ} \mathrm{C}\right.$ vs $\left.0.2^{\circ} \mathrm{C}\right)$. In this context Edwards, Hill, \& Jones (1975) showed, that the rate of muscle temperature rise has a positive correlation to the exercise intensity (in $\%$ of maximum voluntary contraction). In addition, Krustrup et al. (2003) demonstrate, that muscle heat production is related with the ATP turnover rate and higher intensities showed a higher ATP turnover rate, a higher blood flow and a higher muscle temperature in the stressed muscle. In the present study, higher intensities were also related to higher $\mathrm{T}_{\text {max }}$ values but due to the small sample size, these findings were not significant but a bigger sample size maybe would show significant differences.

In the unloaded arm, the $\mathrm{T}$ patterns were qualitative similar to that in the loaded arm (Figure 3). However, the important quantitative parameters of the study, such as $T_{\mathrm{S} 3}$, $T_{\max }, T_{\max }-T_{30}$ and $T_{30}$ were significantly lower than in the loaded arm (Table 4). Only a significant time effect could be observed at 30\% 1RM (Table 3). T rose at 30\% 1RM about $0.5^{\circ} \mathrm{C}\left(\mathrm{T}_{\max }\right)$ whereas at $50 \%$ and $70 \% 1 \mathrm{RM}$, T decreased until $\mathrm{T}_{\mathrm{S} 3}$ and then increased slightly compared to $\mathrm{T}_{\text {rest }}$.

For the comparison of the calculated $\mathrm{T}$ changes with the values of the existing studies, it must be noted, that the methods in the studies were very different (skin temperature calculation, measurement time points, number of sets, exercise intensity) (Formenti et al., 2013; Formenti et al., 2016; Fröhlich et al., 2014; Neves et al., 2014; Neves et al., 2016). The rise of $\mathrm{T}$ to the initial value determined in this study is much higher compared to Formenti et al. (2016), where only one set was performed, whereas in the present study, three sets were completed. This different training load may be the cause of the higher T-values. In other investigations with several sets, an increase of $\mathrm{T}$ of $1{ }^{\circ} \mathrm{C}$ in the biceps area was shown directly after the load (Neves et al., 2015) and in two individual participants, an increase of $2^{\circ} \mathrm{C}$ and $3.5^{\circ} \mathrm{C}$ was shown (Neves et al., 2014). In contrast, Neves et al. (2016) found a decrease of $\mathrm{T}$ in the biceps region after four sets of biceps curls at 70 and $85 \%$ of $10 \mathrm{RM}$. Skin temperature fell by approximately $2^{\circ} \mathrm{C}$ in the loaded arm and around $2.5^{\circ} \mathrm{C}$ in the unloaded arm. The author explained this contrasting reaction with the kind of sample, untrained women with larger subcutaneous fat layer and less muscle volume. Therefore, future studies could compare the development of $\mathrm{T}$ after resistance exercise in men and women with a large range of subcutaneous fat layer.

This study found also positive correlations of the 1RM and $\mathrm{T}$ changes after exercise $\left(\mathrm{T}_{\mathrm{S} 3}\right.$ and $\left.\mathrm{T}_{\max }\right)$. According to Krustrup et al. (2003), individuals with a higher 1RM generate a higher power and have a higher ATP turnover rate and therefore a higher muscle temperature. Despite we did not measured ATP turnover rate, this can possibly explain the higher T-values on the skin surface of the participants with a higher 1RM.

Furthermore, we found correlations of BST and the changes of $\mathrm{T}$ after the biceps curls. Lower BST values correlate with higher $\mathrm{T}_{\mathrm{S} 3}$ and $\mathrm{T}_{\max }$ values but this correlation only reached significance at the $50 \% 1 \mathrm{RM}$ condition. These findings can be confirmed by Priego Quesada et al. (2015), where participants with larger thigh skinfold showed lower 
$\Delta \mathrm{T}$-values in vastus lateralis and rectus femoris in an incremental cycle exercise $(r>-0.7)$.

The present study was carried out under strict standardized conditions. The frequency of movement was standardized and precisely controlled by a metronome and the room temperature and humidity were maintained at a constant level. A room temperature of $22.1 \pm 0.5^{\circ} \mathrm{C}$ was perceived by the participants as agreeable, to ensure they were not in any discomfort during the 45 minute examination. Furthermore, the 15-minute acclimatization time was exactly maintained so that the unclothed upper body of the participants could adapt to the room temperature. Most studies had acclimatization times of 10 to 20 minutes (Bartuzi et al., 2012; Formenti et al., 2013; Formenti et al., 2016; Fröhlich et al., 2014; Neves et al., 2014; Neves et al., 2016). Marins et al. (2014) recommended an acclimatization time for at least $10 \mathrm{~min}$, but it is uncertain, whether longer periods of acclimatization decisively influence the $\mathrm{T}$ patterns. Therefore, following studies should examine the consequences of different acclimatization periods on $\mathrm{T}$ during and after exercise.

The study showed that it is possible to visualize the primary used muscles in strength training with a simple and contactless method like IRT and that the stressed muscle groups can be detected through measuring the surface warming of the skin even at low intensities. Due to this measuring method, this visualization can also be used as real-time feedback, because infrared images can be viewed and analyzed in real time.

Future studies should compare the influence on $\mathrm{T}$ after resistance exercises with a variation of different load characteristics like number of sets, number of repetitions, movement velocity, rest between the sets and kind of contraction (concentric, eccentric, static). In addition, the influence of the trained muscle group, age, sex, skinfold thickness, acclimatization time, room temperature and humidity on exercise-associated changes of $\mathrm{T}$ need further investigation.

\section{CONCLUSION}

This study observed an acute increase of $\mathrm{T}$ in the stressed muscle region, which could be independent of the exercise intensity. Every participant showed a rise of $\mathrm{T}$ at 30, 50 and $70 \% 1 \mathrm{RM}$ and the patterns of the $\mathrm{T}$ changes were relatively homogenous and reproducible. Non-contact IRT seems to be applicable to identify the primary used functional muscles in resistance training but this method seems not suitable to differentiate between exercise intensity from 30 to $70 \% 1 \mathrm{RM}$.

\section{REFERENCES}

Baechle, T. R., \& Earle, R. W. (Eds.). (2008). Essentials of strength training and conditioning (3. ed.). Champaign, IL: Human Kinetics.

Balci, G. A., Basaran, T., \& Colakoglu, M. (2016). Analysing visual pattern of skin temperature during submaximal and maximal exercises. Infrared Physics \& Technology, 74, 57-62. https://doi.org/10.1016/j.infrared.2015.12.002

Bartuzi, P., Roman-Liu, D., \& Wisniewski, T. (2012). The influence of fatigue on muscle temperature. International journal of occupational safety and ergonomics: JOSE,
18(2), 233-243. https://doi.org/10.1080/10803548.2012 .11076931

Chudecka, M. (2013). Use of thermal imaging in the evaluation of body surface temperature in various physiological states in patients with different body compositions and varying levels of physical activity. Central european journal of sport sciences and medicine, 2(2), 15-20.

Chudecka, M., Lubkowska, A., Leznicka, K., \& Krupecki, K. (2015). The use of thermal imaging in the evaluation of the symmetry of muscle activity in various types of exercises (symmetrical and asymmetrical). Journal of human kinetics, 49, 141-147. https://doi.org/10.1515/ hukin-2015-0116

Costello, J., Stewart, I. B., Selfe, J., Karki, A. I., \& \& Donnelly, A. (2013). The use of thermal imaging in sports medicine research: a short report. International Sportmed Journal, 14(2), 94-98.

Das, P., Vardasca, R., \& Mendes, J. G. (Eds.). (2017). Innovative research in thermal imaging for biology and medicine. Advances in Medical Technologies and Clinical Practice: IGI Global.

Edwards, R. H., Hill, D. K., \& Jones, D. A. (1975). Heat production and chemical changes during isometric contractions of the human quadriceps muscle. The Journal of physiology, 251(2), 303-315.

Formenti, D., Ludwig, N., Gargano, M., Gondola, M., Dellerma, N., Caumo, A., \& Alberti, G. (2013). Thermal imaging of exercise-associated skin temperature changes in trained and untrained female subjects. Annals of biomedical engineering, 41(4), 863-871. https://doi. org/10.1007/s10439-012-0718-x

Formenti, D., Ludwig, N., Trecroci, A., Gargano, M., Michielon, G., Caumo, A., \& Alberti, G. (2016). Dynamics of thermographic skin temperature response during squat exercise at two different speeds. Journal of thermal biology, 59, 58-63. https://doi.org/10.1016/j. jtherbio.2016.04.013

Fröhlich, M., Ludwig, O., Kraus, S., \& Felder, H. (2014). Changes in skin surface temperature during muscular endurance indicated strain - an explorative study. International Journal of Kinesiology \& Sports Science, 2(3), 23-27.

Fröhlich, M., Ludwig, O., Zeller, P., \& Felder, H. (2015). Changes in skin surface temperature after a 10 -minute warm-up on a bike ergometer. International Journal of Kinesiology \& Sports Science, 3(3), 13-17.

Gray, S. R., Soderlund, K., Watson, M., \& Ferguson, R. A. (2011). Skeletal muscle ATP turnover and single fibre ATP and PCr content during intense exercise at different muscle temperatures in humans. Pflugers Archiv: European journal of physiology, 462(6), 885-893. https://doi.org/10.1007/s00424-011-1032-4

Hildebrandt, C., Raschner, C., \& Ammer, K. (2010). An overview of recent application of medical infrared thermography in sports medicine in Austria. Sensors (Basel), 10(5), 4700-4715. https://doi.org/10.3390/s100504700

ISO 2009 Medical electrical equipment-deployment, implementation and operational guidelines for identifying 
febrile humans using a screening thermograph. TR 13154:2009 ISO/TR 8-600.

Jiang, L. J., Ng, E. Y. K., Yeo, A. C. B., Wu, S., Pan, F., Yau, W. Y., Yang, Y. (2005). A perspective on medical infrared imaging. Journal of medical engineering \& technology, 29(6), 257-267. https://doi.org/10.1080/03091900 512331333158

Kenny, G. P., Reardon, F. D., Zaleski, W., Reardon, M. L., Haman, F., \& Ducharme, M. B. (2003). Muscle temperature transients before, during, and after exercise measured using an intramuscular multisensor probe. Journal of applied physiology (Bethesda, Md.: 1985), 94(6), 2350-2357. https://doi.org/10.1152/ japplphysiol.01107.2002

Kenny, G. P., Webb, P., Ducharme, M. B., Reardon, F. D., \& Jay, O. (2008). Calorimetric measurement of postexercise net heat loss and residual body heat storage. Medicine and science in sports and exercise, 40(9), 1629-1636. https://doi.org/10.1249/MSS.0b013e31817751cb

Krustrup, P., Ferguson, R. A., Kjaer, M., \& Bangsbo, J. (2003). ATP and heat production in human skeletal muscle during dynamic exercise: Higher efficiency of anaerobic than aerobic ATP resynthesis. The Journal of physiology, 549(Pt 1), 255-269. https://doi.org/10.1113/ jphysiol.2002.035089

Lahiri, B. B., Bagavathiappan, S., Jayakumar, T., \& Philip, J. (2012). Medical applications of infrared thermography: A review. Infrared Physics \& Technology, 55(4), 221235. https://doi.org/10.1016/j.infrared.2012.03.007

Ludwig, N., Formenti, D., Trecroci, A., Gargano, M., \& Alberti, G. (2014). Comparison of image analysis methods in skin temperature measurements during physical exercise. Quantitative InfraRed Thermography, Bordeaux 7-11 July.

Marins, J. C. B., Moreira, D. G., Cano, S. P., Quintana, M. S., Soares, D. D., Fernandes, A. d. A., Amorim, P. R. d. S. (2014). Time required to stabilize thermographic images at rest. Infrared Physics \& Technology, 65, 30-35. https://doi.org/10.1016/j.infrared.2014.02.008

Merla, A., Mattei, P. A., Di Donato, L., \& Romani, G. L. (2010). Thermal imaging of cutaneous temperature modifications in runners during graded exercise. Annals of biomedical engineering, 38(1), 158-163. https://doi. org/10.1007/s10439-009-9809-8

Neves, E. B., Cunha, R. M., Rosa, C., Antunes, N. S., Felisberto, I. M. V., Vilaça-Alves, J., \& Reis, V. M. (2016). Correlation between skin temperature and heart rate during exercise and recovery, and the influence of body position in these variables in untrained women. Infrared Physics \& Technology, 75, 70-76. https://doi. org/10.1016/j.infrared.2015.12.018

Neves, E. B., Moreira, T. R., Lemos, R., Vilaça-Alves, J., Rosa, C., \& Reis, V. M. (2015). Using skin temperature and muscle thickness to assess muscle response to strength training. Revista Brasileira de
Medicina do Esporte, 21(5), 350-354. https://doi. org/10.1590/1517-869220152105151293

Neves, E. B., Vilaça-Alves, J., Krueger, E., \& Reis, V. M. (2014). Changes in skin temperature during muscular work: a pilot study. Pan Am JMed Thermol, 1(1), 11-15.

Neves, E. B., Vilaça-Alves, J., Moreira, T. R., de Lemos, Rui Jorge Canário Alvares, \& Reis, V. M. (2016). The thermal response of biceps brachii to strength training. Gazzetta medica italiana, 175(10), 391-399.

Priego Quesada, J. I., Carpes, F. P., Bini, R. R., Salvador Palmer, R., Perez-Soriano, P., \& Cibrian Ortiz de Anda, R. M. (2015). Relationship between skin temperature and muscle activation during incremental cycle exercise. Journal of thermal biology, 48, 28-35. https:// doi.org/10.1016/j.jtherbio.2014.12.005

Priego Quesada, J. I. (Ed.). (2017). Application of infrared thermography in sports science. Biological and Medical Physics, Biomedical Engineering. Cham: Springer. Retrieved from http://dx.doi. org/10.1007/978-3-319-47410-6

Priego Quesada, J. I., Martínez, N., Salvador Palmer, R., Psikuta, A., Annaheim, S., Rossi, R. M., PérezSoriano, P. (2016). Effects of the cycling workload on core and local skin temperatures. Experimental Thermal and Fluid Science, 77, 91-99. https://doi.org/10.1016/j. expthermflusci.2016.04.008

Ring, E. F. J., \& Ammer, K. (2012). Infrared thermal imaging in medicine. Physiological measurement, 33(3), 46. https://doi.org/10.1088/0967-3334/33/3/R33

Sahlin, K., Katz, A., \& Henriksson, J. (1987). Redox state and lactate accumulation in human skeletal muscle during dynamic exercise. Biochemical Journal, 245(2), 551-556. https://doi.org/10.1042/bj2450551

Schlager, O., Gschwandtner, M. E., Herberg, K., Frohner, T., Schillinger, M., Koppensteiner, R., \& Mlekusch, W. (2010). Correlation of infrared thermography and skin perfusion in Raynaud patients and in healthy controls. Microvascular research, 80(1), 54-57. https://doi. org/10.1016/j.mvr.2010.01.010

Sillero-Quintana, M., Gomez-Carmona, P. M., \& FernándezCuevas, I. (2017). Infrared thermography as a means of monitoring and preventing sports injuries. In P. Das, R. Vardasca, \& J. G. Mendes (Eds.), Advances in Medical Technologies and Clinical Practice. Innovative research in thermal imaging for biology and medicine (pp. 165-198). IGI Global. https://doi.org/10.4018/978-1-5225-2072-6.ch008

Stienen, G. J., Kiers, J. L., Bottinelli, R., \& Reggiani, C. (1996). Myofibrillar ATPase activity in skinned human skeletal muscle fibres: Fibre type and temperature dependence. The Journal of physiology, 493 (Pt 2), 299-307.

Wang, H., Wade, Jr., Dwight R., \& Kam, J. (2004). IR imaging of blood circulation of patients with vascular disease. In D. D. Burleigh, K. E. Cramer, \& G. R. Peacock (Eds.): SPIE Proceedings, Defense and Security (p. 115). SPIE. https://doi.org/10.1117/12.545899 